\title{
Comparisons of Fuzzy Logic and Propotional Integral Differential Controllers in Controlling Buck-boost DC- DC Converter
}

\author{
Maksum Pinem ${ }^{1 *}$, Bayu Iqbal Siregar ${ }^{2}$, Syafruddin $\mathrm{HS}^{3}$, Suherman $^{4}$ \\ \{ maksum.pinem@gmail.com* $\}$ \\ 1,2,3,4Electrical Engineering Department, Universitas Sumatera Utara, Indonesia
}

\begin{abstract}
In order to reduce energy wasted on multi-level direct current (DC) voltage supplier, DC to DC is employed. However, as conversion may exert wasted dropped power, buck-boost conversion with artificial intelligent technique is applied. This paper discusses DC-DC buck-boost conversion for direct current motor load by using fuzzy logic and proportional integral differential (PID) controls to set optimal duty cycle to reduce wasted energy. By using simulations, it is proven fuzzy logic controlled converter outperforms PID controlled converter. Fuzzy logic controlled DC-DC buck-boost converter produces $0.53 \mathrm{~ms}$ lower rise time, up to $151 \mathrm{~V}$ higher voltages, almost three times output current and lower average error.
\end{abstract}

Keywords: DC-DC converter, buck-boost converter, fuzzy logic, proportional integral differential (PID).

\section{Introduction}

The increasing population is followed by the riseonelectrical energy demands. The electronic power converters such as uninterruptible power supply (UPS), charger, and electric regulator play important role in energy supply. AC-DC and DC-DC converters involve rectifying, filtering, and regulating processes. The rectifying, filtering and regulating are main problem on AC-DC conversion, while regulator is the main process on DC-DC conversion (Helmy M H, Onny S, 2016).

There are several regulating techniques employed by AC-DC and DC-DC converters, one of them is buck converter. Buck voltage converter is when the output voltage is smaller than the input one. The boost converter exerts greater output than the input voltage. If the output voltage is larger or smaller than the input voltage, the converter is called buck-boost converter(Rashid, no date).

As DC-DC converter efficiency as in mobile device is very important (Suherman, Mubarakah, N., O. Wiranata, 2018)control techniques are employed so that the wasted energy can be reduced. Some control techniques are using proportional integral differential (PID) andfuzzy logic.

In previous studies, the proportional integral (PI) control method was used on an AC-DC buck-boost converter to improve the power factor (Rajalakshmi G, Sivaranjani K, no date). PID and fuzzy logic are used by Faisal (Faisal, A., \& Hasan, 2018). The open loop sliding control (OLSC) is employed to increase total harmonic distortion (THD) and power factor (Periyasamy, 2012). The fuzzy logic controlhas also been used on boost converter on(Shobana $\mathrm{P}$, GeethaN, 2012). This paper focuses on the DC-DC conversion using buck-boost converter 
withPID and fuzzy logic to regulate the duty cycle. The evaluated load is a DC motor where its torque is observed.

The buck-boost regulator produces an output voltage smaller or greater than its input voltage. This type of regulator is also called an inverting regulator. The set of buck-boost regulator circuit is shown in the Figure 1.Circuit work can be divided into two modes. During mode 1 , transistor $\mathrm{Q}_{1} \mathrm{ON}$ and diode $\mathrm{D}_{\mathrm{m}}$ is reverse biased. Energy stored in $\mathrm{L}$ flows to load. In mode 2, Q1 is off, input voltage is cut, and diode is forward biased by the voltage in capacitor.

The output voltage depends on duty cycle of transistor switch, $D=\frac{t_{1}}{T}$, determined by Equation 1.

$\mathrm{V}_{\mathrm{a}}=\left(\frac{1}{\mathrm{~T}} \int_{0}^{\mathrm{DT}} \mathrm{v}_{0}^{2} \mathrm{dt}\right)^{\frac{1}{2}}=\sqrt{\mathrm{D}} \mathrm{V}_{\mathrm{s}}$

In mode 2, the generated voltage across the load is:

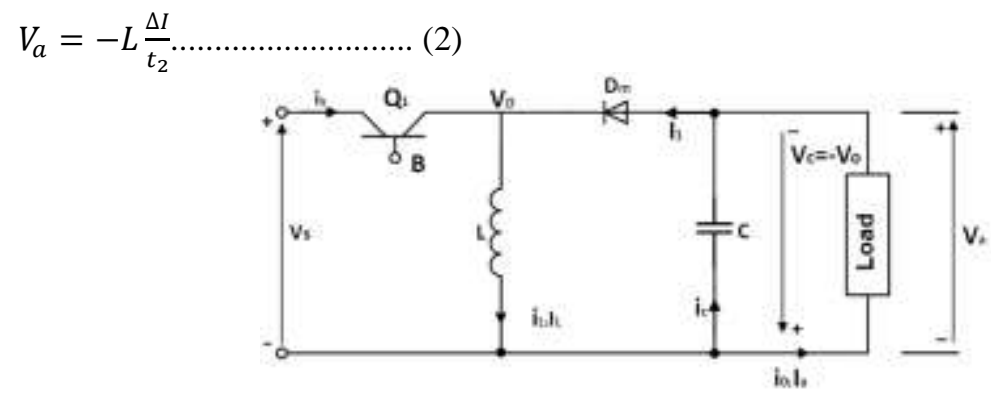

Fig. 1. Circuit diagram of DC-DC buck-boost converter with control system

\section{Research Method}

This paper evaluates the AC to DC converter with diode bridge rectifier and a power MOSFET as a switching component that are controlled by PWM signal.

The magnitude of the output voltage is set according to the duty cycle (D) of PWM. If D $>0.5$, then the output voltage $(\mathrm{Va})$ will be greater than the input voltage $(\mathrm{Vs})$. Whereas if $\mathrm{D}$ $<0.5$ then the output voltage will be smaller than input voltage, and $\mathrm{Vs}=\mathrm{Va}$ at $\mathrm{D}=0.5$ [4]. The load is a DC motor with its output torque is measured.

The circuit is modeled as depicted in Figure 2. The PID and fuzzy logic on buck-booster converter is applied to feedback output voltage to MOSFET.

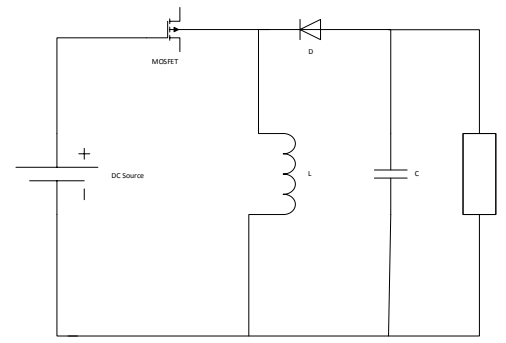

Fig. 2. Circuit model of DC-DC buck-boost converter 


\subsection{Simulated Fuzzy Logic Control}

Figure 3 shows the schematic diagram of buck-boost DC-DC converter with fuzzy controlling the MOSFET.The voltage from the source that goes into the system will first enter into the buck-boost converter, then the voltage will go out to the DC machine. The output voltage of the buck boost converter will then fit into the fuzzy logic input.Fuzzy controller take reference and input voltages as the error input, combines its error with the delayed error, adjusts repeating sequence by following certain rules.Then the output of fuzzy logic goes back to the MOSFET and sets the buck-boost converter.

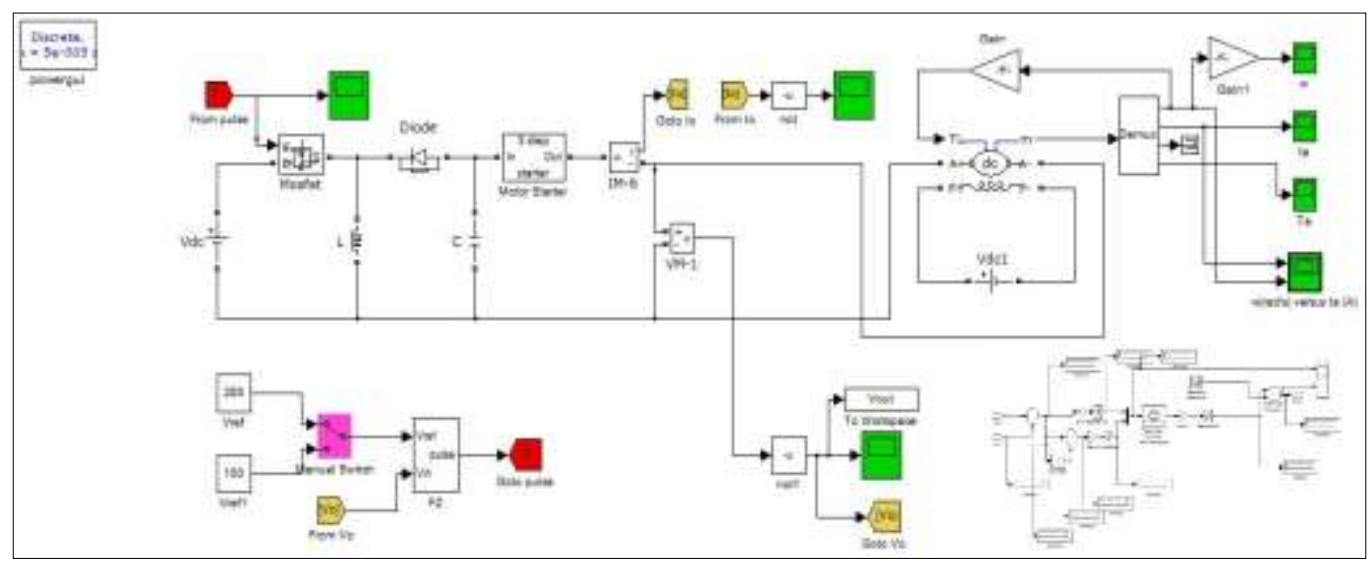

Fig. 3.Simulated model of DC-DC buck-boost converter with Fuzzy

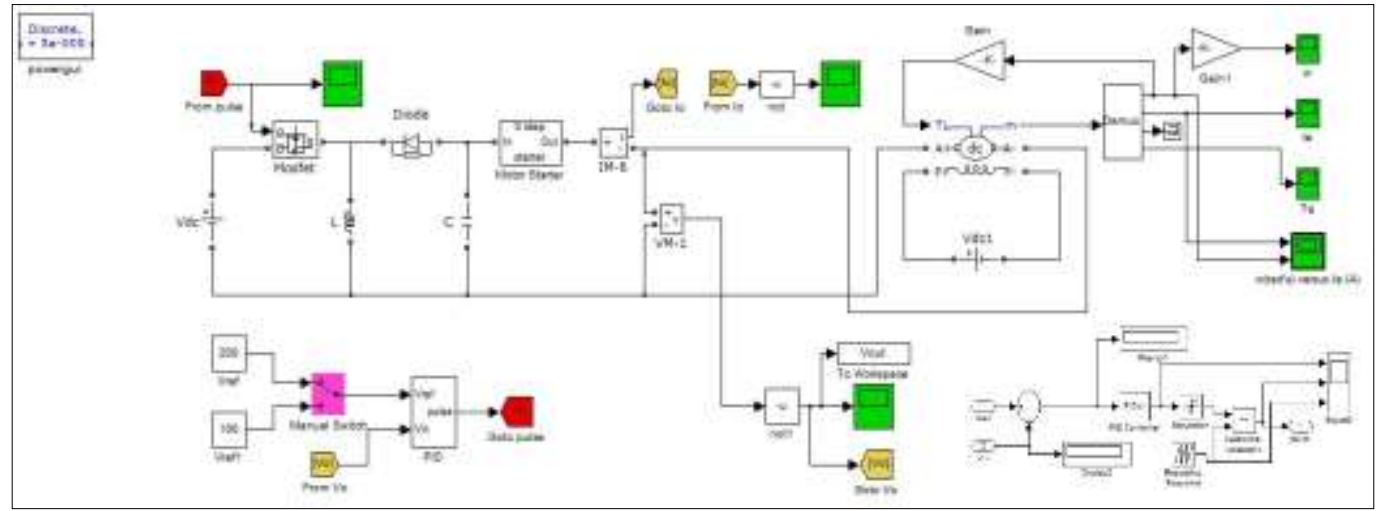

Fig. 4. Simulated model of DC-DC buck-boost converter with PID

\subsection{Simulated PID Control}

Figure 4 shows the schematic diagram of buck-boost DC-DC converter with PID controlling the MOSFET. The voltage from the source that goes into the system will first enter into the buck-boost converter, then the voltage will go out to the DC machine. The output voltage of the buck boost converter will then enter into the PID input.The PID controller takes reference and input voltage as an error input for the PID controller, measures the saturation and compares it to the repeating sequence to drive MOSFET.Then the output of the PID will return to the MOSFET and set the buck-boost converter. 


\subsection{Fuzzy Logic Rules}

Input voltage error and voltage delta error has seven membership functions. The fuzzy controller compares the two membership functions of the voltage and produces one output. Fuzzy rules are based on the working principles of the system. Basic rules adjust the duty cycle for MOSFET in DC-DC buck boost converter based on change in fuzzy logic controller input. The number of rules is customized according to your wish. Rules consist of 49 rules based on seven membership functions in input variables. The fuzzy rules are written as in Table I

Tabel 1. Fuzzy logic control rules

\begin{tabular}{cccccccc}
\hline E/dE & NL & NM & NS & ZO & PS & PM & PL \\
\hline NL & NL & NL & NL & NM & NS & ZO & PS \\
\hline NM & NL & NL & NL & NM & NS & ZO & PS \\
\hline NS & NL & NL & NM & NS & ZO & PS & PM \\
\hline ZO & NL & NM & NS & ZO & PS & PM & PL \\
\hline PS & NM & NS & ZO & PS & PM & PL & PL \\
\hline PM & NS & ZO & PS & PM & PL & PL & PL \\
\hline PL & ZO & PS & PM & PL & PL & PL & PL \\
\hline
\end{tabular}

Explanation :

PL : Positive Large

PM : Positive medium

PS : Positive Small

ZO : Zero Order

NL : Negative Large

NM : Negative Medium

NS : Negative Small

\section{Results}

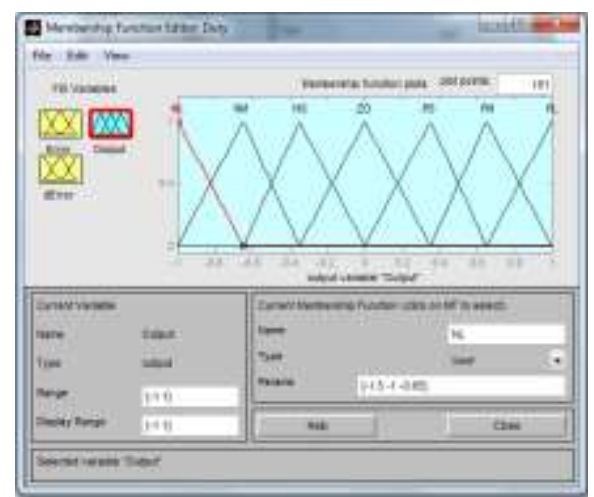

Fig. 5.Variable membership function

Figure 5shows the comparisons of voltages, currents and torques for both fuzzy logic and PID controllers for reference voltage of $180 \mathrm{~V}$.

As fuzzy logic controller recalculating errors as well as following pre-studied rules, it performs better controlling than PID. Fuzzy logic generates the smaller rise time compared to PID, so that voltage is quickly achieving its stable value. 

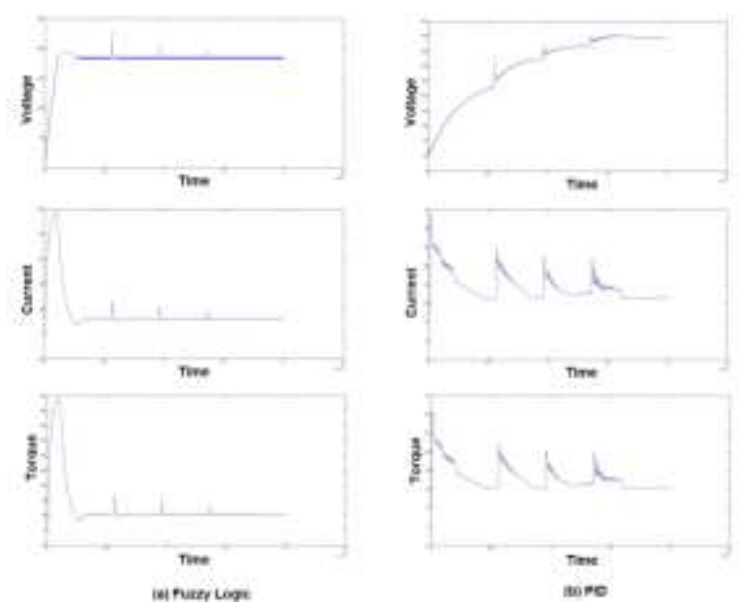

Fig. 6. Fuzzy logic versus PID for Vref $=180 \mathrm{~V}$

Fuzzy rise time decreases up to $1.07 \mathrm{~ms}$, while PID reaches only $1.6 \mathrm{~ms}$.Further, fuzzy logic generates higher voltages and currents than PID. Fuzzy maximum voltage reaches $304 \mathrm{~V}$ compared to $154.4 \mathrm{~V}$ of PID.

Table 2. The comparison PID and Fuzzy Logic

\begin{tabular}{clcc}
\hline \multirow{2}{*}{ No } & \multicolumn{1}{c}{ Parameters } & \multicolumn{1}{c}{$\mathrm{V}_{\text {ref } 180 \mathrm{~V}}$} \\
\cline { 3 - 4 } & & Fuzzy Logic & PID \\
\hline 1 & Rise time & $1.07 \mathrm{~ms}$ & $1.61 \mathrm{~ms}$ \\
\hline 2 & Peak time & $5.6 \mathrm{~ms}$ & $5.6 \mathrm{~ms}$ \\
\hline 3 & Max Overshoot $\mathrm{V}_{\text {out }}$ & $227.6 \mathrm{~V}$ & $154.4 \mathrm{~V}$ \\
\hline 4 & Min Overshoot $\mathrm{V}_{\text {out }}$ & - & - \\
\hline 5 & Max overshoot Iout & $97.8 \mathrm{~A}$ & $33.98 \mathrm{~A}$ \\
\hline 6 & Min overshoot Iout & $6.35 \mathrm{~A}$ & $11.18 \mathrm{~A}$ \\
\hline 7 & Max overshoot Torque & $176.1 \mathrm{~N} . \mathrm{m}$ & $61.19 \mathrm{~N} . \mathrm{m}$ \\
\hline 8 & Min overshoot Torque & $11.68 \mathrm{~N} . \mathrm{m}$ & $20.25 \mathrm{~N} . \mathrm{m}$ \\
\hline
\end{tabular}

The higher voltage and current generated by fuzzy controller lead to the higher torque on DC motor as the load of the DC-DC buck-boost converter. Table 2 shows the compared parameters as results of fuzzy logic and PID controlling the DC-DC buck-boost converter.

Finally, as the converter generates the output voltage based on the reference, output voltage should be as close as possible to its reference. The output of fuzzy logic controlled DC-DC converter produces smaller error percentage than PID controlled DC-DC converter as shown in Table 3.

Table 3. The comparison PID and Fuzzy Logic (cont)

\begin{tabular}{llcccc}
\hline \multirow{2}{*}{ No } & \multirow{2}{*}{ Parameters } & \multicolumn{2}{c}{$\mathrm{V}_{\text {ref } 200 \mathrm{~V}}$} & \multicolumn{2}{c}{$\mathrm{V}_{\text {ref } 240 \mathrm{~V}}$} \\
\cline { 3 - 6 } & & Fuzzy Logic & PID & Fuzzy Logic & PID \\
& & & & \\
\hline 1 & Rise time & $1.20 \mathrm{~ms}$ & $1.6 \mathrm{~ms}$ & $1.49 \mathrm{~ms}$ & $1.6 \mathrm{~ms}$ \\
\hline 2 & Peak time & $5.6 \mathrm{~ms}$ & $5.6 \mathrm{~ms}$ & $5.6 \mathrm{~ms}$ & $5.6 \mathrm{~ms}$ \\
\hline 3 & Max Overshoot $\mathrm{V}_{\text {out }}$ & $254.1 \mathrm{~V}$ & $154.4 \mathrm{~V}$ & $304 \mathrm{~V}$ & $153.2 \mathrm{~V}$ \\
\hline
\end{tabular}




\begin{tabular}{clcccc}
\hline 4 & Min Overshoot $V_{\text {out }}$ & - & - & - & - \\
\hline 5 & Max overshoot Iout & $98.22 \mathrm{~A}$ & $33.91 \mathrm{~A}$ & $98.22 \mathrm{~A}$ & $33.99 \mathrm{~A}$ \\
\hline 6 & Min overshoot Iout & $8.28 \mathrm{~A}$ & $11.118 \mathrm{~A}$ & $13.6 \mathrm{~A}$ & $11.15 \mathrm{~A}$ \\
\hline 7 & Max overshoot Torque & $176.8 \mathrm{~N} . \mathrm{m}$ & $61.18 \mathrm{~N} . \mathrm{m}$ & $176.7 \mathrm{~N} . \mathrm{m}$ & $61.48 \mathrm{~N} . \mathrm{m}$ \\
\hline 8 & Min overshoot Torque & $14.82 \mathrm{~N} . \mathrm{m}$ & $20.12 \mathrm{~N} . \mathrm{m}$ & $24.59 \mathrm{~N} . \mathrm{m}$ & $20.11 \mathrm{~N} . \mathrm{m}$ \\
\hline
\end{tabular}

Table 3. Error percentages

\begin{tabular}{ccc}
\hline $\mathrm{V}_{\text {ref }}$ & \multicolumn{2}{c}{ Error percentage } \\
\cline { 2 - 3 } & Fuzzy logic & PID \\
\hline $180 \mathrm{~V}$ & $2.41 \%$ & $1.75 \%$ \\
\hline $200 \mathrm{~V}$ & $2.17 \%$ & $10.95 \%$ \\
\hline $240 \mathrm{~V}$ & $1.79 \%$ & $25.56 \%$ \\
\hline
\end{tabular}

\section{Conclusion}

DC-DC buck-boost converter is able to produce output voltage higher or lower than its input. The output is determined by the duty cycle of MOSFET switching. This can be controlled by using certain controlled techniques. This paper has compared the performances of DC-DC buck-boost converter controlled by either fuzzy logic controller or PID. The results show that fuzzy logic outperforms of PID.

DC-DC converter controlled by fuzzy logic produces at least $0.53 \mathrm{~ms}$ lower rise time, up to $151 \mathrm{~V}$ higher voltage, and almost three times output current. In term of error percentage, fuzzy logic controlled converter produces much lower average error.

DC-DC buck boost converter with fuzzy logic control does have a larger Max Overshoot compared to PID control, but it only lasts for a while and fuzzy logic control reaches stable faster than PID control or in other words waves with fuzzy logic control faster becomes wave direction and slightly ripple whereas with PID control takes a long time into direct wave and there are still many ripples on the wave. Then the error percentage with the fuzzy logic control is very small compared to the PID control and there is an increasingly smaller inclination if the Vreference is greater while the PID control is the opposite, the percentage error is greater if the Vreference is greater.

From both controls, PID and fuzzy logic, the simulated fuzzy logic gives better performance of DC-DC buck boost converter compared to PID control.

\section{References}

[1] Faisal, A., \& Hasan, S. (2018) 'Simulation comparison of proportional integral derivative and fuzzy logic in controlling AC-DC buck boost converter', Journal of Physics: Conference Series, 978, p. 012074.

[2] Helmy M H, Onny S, H. S. (2016) 'No Title', JNTETI, 5(1).

[3] Periyasamy (2012) 'No Title', IJERA, 2(5).

[4] Rajalakshmi G, Sivaranjani K, A. K. (no date) 'Microcontroller Implementation of Power Factor Improvement Strategy for a Buck-Boost AC-DC Converter', IEEE, 9781-4799-3826-1.

[5] Rashid, H. (no date) 'Power Electronics: Circuit, Devices, and Aplication.Third Edition, 2004'.

[6] Shobana P, GeethaN, G. divel J. (2012) 'Enhancement of Power Quality of AC-DC 
Boost Converter with HCC and FLC-A Comparative Study', IEEE 978-1-4673-0210-4. 2012.

[7] Suherman, Mubarakah, N., O. Wiranata, and S. T. K. (2018) 'Energy-signal quality trade-offs in a WiMAX mobile station with a booster amplifier', IOP Conference Series: Materials Science and Engineering, 309(IOP Publishing). 